\title{
Admission to hospital for effects of heat and light: NSW, 1993-94 to 2003-04
}

\author{
Paul J. Beggs ${ }^{\mathrm{A}, \mathrm{B}}$ and Pavla Vaneckova ${ }^{\mathrm{A}}$ \\ A Department of Physical Geography, Macquarie University \\ ${ }^{\mathrm{B} C o r r e s p o n d i n g ~ a u t h o r . E m a i l: ~ p a u l . b e g g s @ m q . e d u . a u ~}$
}

\begin{abstract}
The study examined the hospital admission rates and characteristics of patients experiencing severe heat-related morbidity in NSW using data from the NSW Health Inpatient Statistics Collection. The study covered the 11-year period from July 1993 to June 2004. ICD-10-AM. codes examined included T67 (effects of heat and light). There was an average of 91 admissions for each year due to a principal diagnosis of the effects of heat and light, with consistently more males than females admitted (1.7:1). Many of the admissions $(39 \%)$ were of people 65 years of age or older. Most admissions (49\%) occurred in the summer months of December and January.
\end{abstract}

The 2003 heat wave in Europe and climate change caused by humans have heightened interest in the relationships between climate and public health generally, and heatrelated morbidity and mortality in particular. ${ }^{1-3}$ While many studies have examined heat-related mortality, in some cases associated with specific heat waves, fewer studies have examined heat-related morbidity; for example, by analysis of hospital records. ${ }^{4-10}$ The study examines the hospital admission rates and patient characteristics for severe heat-related morbidity in New South Wales (NSW) by analysing routinely-collected hospital inpatient data.

\section{Methods}

Data used in the study were from the NSW Health Inpatient Statistics Collection (ISC). The ISC is a census of all admitted patient services provided by NSW public hospitals, public psychiatric hospitals, public multipurpose services, private hospitals and private day procedures centres. ${ }^{11}$ Eleven years of de-identified unit record data were obtained for the period 1 July 1993 to 30 June 2004. Clinical information in the ISC, such as principal diagnosis, additional diagnoses and external causes of injury or poisoning, is coded according to the
International Statistical Classification of Diseases and Related Health Problems - Tenth Revision - Australian Modification (ICD-10-AM). Codes examined included T67 (effects of heat and light), incorporating T67.0 (heatstroke and sunstroke), T67.1 (heat syncope), T67.2 (heat cramp), T67.3 (heat exhaustion, anhydrotic), T67.4 (heat exhaustion due to salt depletion), T67.5 (heat exhaustion, unspecified), T67.6 (heat fatigue, transient), T67.7 (heat oedema), T67.8 (other effects of heat and light) and T67.9 (effect of heat and light, unspecified). External causes Y40-Y59 (drugs, medicaments and biological substances causing adverse effects in therapeutic use) used in addition to a T67 diagnosis were also examined.

Temporal characteristics were examined by analysis of the data by year, month and day of the week. Spatial characteristics were examined through analysis of the data by statistical division. Statistical division is an Australian Standard Geographical Classification defined area, which represents a large, general purpose, regional-type geographic area. Statistical divisions represent relatively homogeneous regions characterised by identifiable social and economic links between the inhabitants and between the economic units within the region. ${ }^{12}$ There are a total of 12 statistical divisions in NSW. Spatial characteristics were also examined through analysis of the data by latitudinal (north or south) and coastal/non-coastal groupings of statistical divisions. The six statistical divisions north of approximately $33.3^{\circ} \mathrm{S}$ were categorised as 'north', and the six statistical divisions south of this latitude were categorised as 'south'. The six statistical divisions with a coastal border were categorised as 'coastal', while those without a coastal border were categorised as 'non-coastal'. Rates were age-standardised using the 1996 Australian population.

\section{Results}

Over the study period, there were a total of 1289 admissions for effects of heat and light as either the principal or an additional diagnosis. Most of these (78\%) were as the principal diagnosis. Where the effects of heat and light were used as an additional diagnosis, the most common principal diagnoses included volume depletion (E86) (14\%), syncope and collapse (R55) (8\%) and other medical care (Z51) (5\%). All effects of heat and light results presented are for the principal diagnosis admissions only. There were an average of 91 admissions each year due to a principal diagnosis of effects of heat and light, although the number varied considerably from year 
Table 1. Summary of the number of admissions for effects of heat and light (T67: ICD-10-AM) in NSW from 1993-94 to 2003-04

\begin{tabular}{|c|c|c|c|c|c|c|}
\hline \multirow[t]{2}{*}{ Year } & \multirow{2}{*}{$\begin{array}{c}\text { Principal } \\
\text { diagnosis } n\end{array}$} & \multirow{2}{*}{$\begin{array}{c}\text { Additional } \\
\text { diagnosis }^{\dagger} n\end{array}$} & \multirow[t]{2}{*}{ Total $n$} & \multirow[t]{2}{*}{$\operatorname{Sex}(M: F)^{*}$} & \multicolumn{2}{|c|}{ Age (years)* } \\
\hline & & & & & Range & Median \\
\hline 1993-94 & 80 & 31 & 111 & $1.3: 1$ & $1-91$ & 50 \\
\hline 1994-95 & 80 & 34 & 114 & $1.4: 1$ & 9-99 & 62 \\
\hline 1995-96 & 55 & 27 & 82 & $1.2: 1$ & $1-97$ & 48 \\
\hline 1996-97 & 78 & 19 & 97 & $1.7: 1$ & $7-97$ & 43 \\
\hline 1997-98 & 101 & 42 & 143 & $1.9: 1$ & $<1-95$ & 48 \\
\hline 1998-99 & 78 & 20 & 98 & $1.5: 1$ & $1-89$ & 58.5 \\
\hline 1999-00 & 50 & 23 & 73 & $1.9: 1$ & $13-98$ & 61.5 \\
\hline 2000-01 & 116 & 36 & 152 & $1.6: 1$ & $2-91$ & 54 \\
\hline 2001-02 & 78 & 17 & 95 & $3.1: 1$ & $<1-99$ & 40.5 \\
\hline 2002-03 & 146 & 27 & 173 & $1.9: 1$ & $<1-103$ & 52.5 \\
\hline 2003-04 & 139 & 20 & 159 & $1.7: 1$ & $<1-96$ & 49 \\
\hline Total & 1001 & 296 & 1297 & $1.7: 1$ & $<1-103$ & 52 \\
\hline \multicolumn{7}{|c|}{$\begin{array}{l}\text { †Tis includes six records for which T67 was also used as the principal diagnosis ( } 1 \text { in } 1993-94,1997-98, \\
\text { 1999-00, 2000-01, 2001-02 and 2002-03), and two records for which T67 was used as more than one } \\
\text { additional diagnosis; additional diagnoses } 2 \text { and } 3 \text { in 1995-96, and additional diagnoses } 1 \text { and } 2 \text { in 2002-03. } \\
\text { ICD-10-AM: International Statistical Classification of Diseases and Related Health Problems - Tenth Revision - } \\
\text { Australian Modification. } \\
\text { Source: NSW Health Inpatient Statistics Collection. }\end{array}$} \\
\hline
\end{tabular}

to year, with a minimum of 50 in 1999-00 and a maximum of 146 in 2002-03 (Table 1). The crude average annual statewide hospital admission rate for the effects of heat and light was 1.5 for every 100000 population. There were consistently more males than females admitted due to a principal diagnosis of effects of heat and light, with the ratio ranging from $1.2: 1$ to $3.1: 1$, and the overall ratio of 1.7:1. Admissions due to a principal diagnosis of effects of heat and light spanned all age groups, with a minimum age of less than 1 year and a maximum of 103 years.

Table 2. Number of admissions for principal diagnosis for each ICD-10-AM sub-category of effects of heat and light (T67) in NSW for each year from 1993-94 to 2003-04

\begin{tabular}{|c|c|c|c|c|c|c|c|c|c|c|}
\hline \multirow[t]{2}{*}{ Year } & \multicolumn{10}{|c|}{ ICD-10-AM sub-category } \\
\hline & $\begin{array}{c}\text { T67.0 } \\
n\end{array}$ & $\begin{array}{c}\text { T67.1 } \\
n\end{array}$ & $\begin{array}{c}\text { T67.2 } \\
n\end{array}$ & $\begin{array}{c}\text { T67.3 } \\
n\end{array}$ & $\begin{array}{c}\mathrm{T} 67.4 \\
n\end{array}$ & $\begin{array}{c}\text { T67.5 } \\
n\end{array}$ & $\begin{array}{c}\mathrm{T} 67.6 \\
n\end{array}$ & $\begin{array}{c}\text { T67.7 } \\
n\end{array}$ & $\begin{array}{c}\mathrm{T} 67.8 \\
n\end{array}$ & $\begin{array}{c}\text { T67.9 } \\
n\end{array}$ \\
\hline 1993-94 & 21 & 2 & 0 & 6 & 2 & 46 & 1 & 0 & 1 & 1 \\
\hline 1994-95 & 23 & 7 & 1 & 8 & 0 & 40 & 0 & 0 & 0 & 1 \\
\hline 1995-96 & 21 & 11 & 1 & 3 & 0 & 18 & 0 & 0 & 0 & 1 \\
\hline 1997-98 & 26 & 16 & 1 & 7 & 2 & 44 & 0 & 0 & 5 & 0 \\
\hline 1998-99 & 27 & 14 & 1 & 1 & 1 & 32 & 0 & 0 & 1 & 1 \\
\hline 1999-00 & 24 & 9 & 0 & 3 & 0 & 13 & 1 & 0 & 0 & 0 \\
\hline 2000-01 & 38 & 19 & 1 & 3 & 1 & 52 & 0 & 0 & 1 & 1 \\
\hline 2001-02 & 31 & 10 & 2 & 5 & 0 & 26 & 2 & 0 & 0 & 2 \\
\hline 2002-03 & 48 & 45 & 2 & 4 & 3 & 43 & 0 & 0 & 1 & 0 \\
\hline 2003-04 & 50 & 36 & 2 & 5 & 3 & 39 & 1 & 0 & 0 & 3 \\
\hline Total N & 329 & 182 & 13 & 51 & 14 & 388 & 5 & 0 & 9 & 10 \\
\hline$\%$ & 33 & 18 & 1 & 5 & 1 & 39 & 1 & 0 & 1 & 1 \\
\hline \multicolumn{11}{|c|}{$\begin{array}{l}\text { ICD-10-AM: International Statistical Classification of Diseases and Related Health Problems - Tenth Revision - Australian Modification. } \\
\text { T67.0: heatstroke and sunstroke; T67.1: heat syncope; T67.2: heat cramp; T67.3: heat exhaustion, anhydrotic; T67.4: heat exhaustion due to salt } \\
\text { depletion; T67.5: heat exhaustion, unspecified; T67.6: heat fatigue, transient; T67.7: heat oedema; T67.8: other effects of heat and light; } \\
\text { T67.9: effect of heat and light, unspecified. }\end{array}$} \\
\hline \multicolumn{11}{|c|}{ Source: NSW Health Inpatient Statistics Collection. } \\
\hline
\end{tabular}


However, many admissions (39\%) were aged 65 years and over. There was no clear trend in any of these annual characteristics over the study period.

Of the ten sub-categories, two were associated with the majority of admissions. These were 'heatstroke and sunstroke' (T67.0) and 'heat exhaustion, unspecified' (T67.5), which accounted for $33 \%$ and $39 \%$ of admissions, respectively (Table 2). Another $23 \%$ of admissions are accounted for by 'heat syncope' (T67.1) and 'heat exhaustion, anhydrotic' (T67.3). The remaining subcategories are associated with very few admissions, each including years during the study period in which there were no associated admissions. The sub-category, heat oedema (T67.7), was not used during the study period.

Analysis of the additional diagnoses and external causes of injury or poisoning associated with $\mathrm{T} 67$ principal diagnosis admissions was restricted to the years 1993-94 to 2001-02 because the last two years of the data (2002-03 and 2003-04) had mixed these two fields. Sixty-three percent of T67 principal diagnosis admissions over the years 1993-94 to 2001-02 had one or more additional diagnoses, with a total of 959 additional diagnoses recorded. The most common additional diagnoses were volume depletion (E86) (15\%) followed by essential (primary) hypertension

Table 3. External causes of injury or poisoning, place of occurrence of external cause of injury and activity when injured for admissions for effects of heat and light (T67) as principal diagnosis in NSW from 1993-94 to 2001-02

\begin{tabular}{|c|c|c|c|}
\hline \multirow{2}{*}{$\begin{array}{l}\text { ICD-10-AM } \\
\text { Code }\end{array}$} & \multirow[t]{2}{*}{ Definition } & \multicolumn{2}{|c|}{ Frequency } \\
\hline & & $n$ & $\%^{+}$ \\
\hline \multicolumn{4}{|c|}{ External cause of injury or poisoning* } \\
\hline $\mathrm{X} 30$ & Exposure to excessive natural heat & 469 & 66 \\
\hline W19 & Unspecified fall & 17 & 2 \\
\hline Y83 & $\begin{array}{l}\text { Surgical operation and other surgical procedures as the cause of abnormal reaction of the } \\
\text { patient, or of later complication, without mention of misadventure at the time of the procedure }\end{array}$ & 15 & 2 \\
\hline $\mathrm{X} 59$ & Exposure to unspecified factor & 14 & 2 \\
\hline W01 & Fall on same level from slipping, tripping or stumbling & 12 & 2 \\
\hline W18 & Other fall on same level & 8 & 1 \\
\hline Y04 & Assault by bodily force & 8 & 1 \\
\hline W92 & Exposure to excessive heat of man-made origin & 7 & 1 \\
\hline Y84 & $\begin{array}{l}\text { Other medical procedures as the cause of abnormal reaction of the patient, or of later } \\
\text { complication, without mention of misadventure at the time of the procedure }\end{array}$ & 7 & 1 \\
\hline X39 & Exposure to other and unspecified forces of nature & 6 & 1 \\
\hline V48 & Car occupant injured in noncollision transport accident & 6 & 1 \\
\hline Y52 & Agents primarily affecting the cardiovascular system & 6 & 1 \\
\hline \multicolumn{4}{|c|}{ Place of occurrence of external cause of injury ${ }^{\#}$} \\
\hline Y920 & Home & 54 & 28 \\
\hline Y929 & Unspecified place of occurrence & 51 & 26 \\
\hline Y922 & School, other institution and public administrative area & 25 & 13 \\
\hline Y924 & Street or highway & 18 & 9 \\
\hline Y928 & Other specified place of occurrence & 8 & 4 \\
\hline Y925 & Trade and service area & 6 & 3 \\
\hline Y923 & Sports and athletics area & 5 & 3 \\
\hline Y921 & Residential institution & 4 & 2 \\
\hline Y926 & Industrial and construction area & 3 & 2 \\
\hline Y927 & Farm & 3 & 2 \\
\hline \multicolumn{4}{|c|}{ Activity when injured ${ }^{\#}$} \\
\hline U73 & Other activity & 144 & 74 \\
\hline U72 & Leisure activity, not elsewhere classified & 5 & 3 \\
\hline U71 & Unspecified sport and exercise activity & 1 & 1 \\
\hline U51 & Team bat or stick sports & 1 & 1 \\
\hline $\begin{array}{l}\text { ICD-10-AM: Int } \\
\text { †Percentage of } \\
\text { *Only the } 12 \text { It } \\
\text { "Only two year } \\
\text { Source: NSW H }\end{array}$ & $\begin{array}{l}\text { lational Statistical Classification of Diseases and Related Health Problems - Tenth Revision - Australian Modific } \\
\text { ling external causes are listed. } \\
\text { ling e00-01 to } 2001-02 \text {. } \\
\text { Ith Inpatient Statistics Collection. }\end{array}$ & ation. & \\
\hline
\end{tabular}




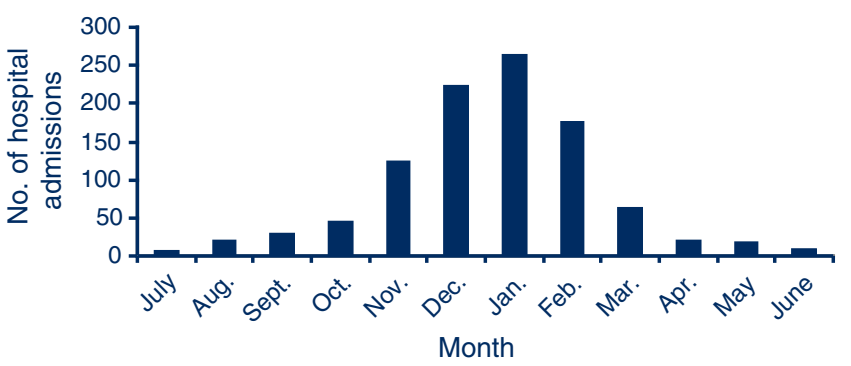

Figure 1. Month of admission for effects of heat and light (ICD-10-AM:T67) in NSW from 1 July 1993 to 30 June 2004. Only principal diagnosis effects of heat and light admissions are shown. ICD-10-AM: International Statistical Classification of Diseases and Related Health Problems - Tenth Revision Australian Modification. Source: NSW Health Inpatient Statistics Collection.

(I10) (7\%). All remaining additional diagnoses categories made up less than $4 \%$ each, with most being used only once. Nearly all the T67 principal diagnosis admissions over the years 1993-94 to 2001-02 (98\%) had an external cause of injury or poisoning (Table 3). The majority of external causes $(66 \%)$ were exposure to excessive natural heat (X30). A more in-depth inspection of this field revealed that approximately $2.4 \%$ of all external causes were a drug, medicament or biological substance causing adverse effects in therapeutic use (Y40-Y59), but only the six admissions with Y52 as the external cause of injury or poisoning are shown in Table 3. Place of occurrence of external cause of injury, and activity when injured, had only been used for two years of the data (2000-01 to 2001-02). For these years, 175 of the 194 records (90\%) had a place of occurrence, and for the majority of these the place of occurrence was either the home, unspecified or school or other institution and public administrative area. Fewer of the records in these years had an activity when injured (150; 77\%). There were only four 'activity when injured' categories used, and most were 'other activity'.

Admission did not vary considerably by day of the week, with the minimum of $126(13 \%)$ occurring on Mondays and the maximum of $166(17 \%)$ occurring on Tuesdays. In contrast, there was considerable monthly variation (Figure 1). Most admissions (49\%) occurred in the first months of summer (December and January), with a further $30 \%$ of admissions occurring in the months either side of this period (November and February). Each of the remaining months included at most $6 \%$ of admissions, and the two winter months of June and July each included 1\% or less of admissions.

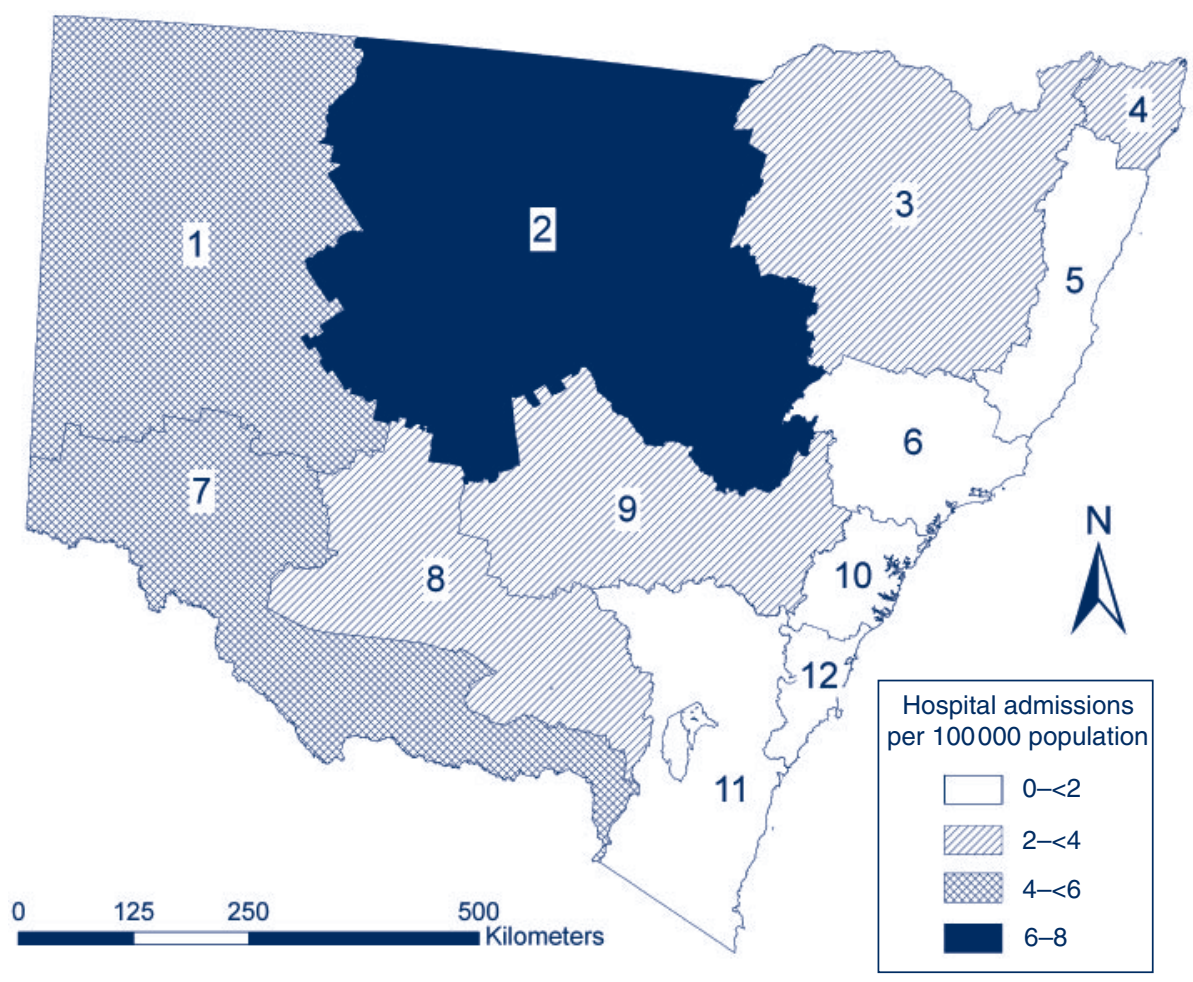

Figure 2. Hospital admission rates for principal diagnosis of effects of heat and light (ICD-10-AM:T67) in Statistical Divisions in NSW from 1 July 1993 to 30 June 2004. Statistical Divisions in NSW: 1: Far West; 2: North Western; 3: Northern; 4: RichmondTweed; 5: Mid-North Coast; 6: Hunter; 7: Murray; 8: Murrumbidgee; 9: Central West; 10: Sydney; 11: South Eastern; 12: Illawarra. ICD-10-AM: International Statistical Classification of Diseases and Related Health Problems - Tenth Revision - Australian Modification. Source: NSW Health Inpatient Statistics Collection. 
There was strong spatial variability in admissions due to a principal diagnosis of effects of heat and light. The annual average hospital admission rate was more than twice as high in the north of the state than in the south $(2.5 v .1 .2$ per 100000), and almost four times higher in the west (non-coastal) than in the east (coastal) (4.3 v. 1.1 per 100000). Consistent with this broad pattern, the Illawarra statistical division in the south-east of the state had the lowest annual average hospital admission rate of 0.7 per 100000 , and the North Western statistical division had the state's highest annual average hospital admission rate of 7.8 per 100000 (Figure 2).

\section{Discussion}

The study examined the hospital admission rates and characteristics of heat-related morbidity in NSW by analysis of routinely collected hospital inpatient data. As indicated in previous studies of hospital admissions, the severe types of heat-related disease (heat exhaustion and heatstroke), were the most common. ${ }^{8}$ Because the ISC does not capture patients who present only to emergency departments, general practices or other non-hospital health services, or those who do not consult any health service, the total magnitude of heat-related illness in NSW is likely to be greater than is indicated in this study.

The seasonal variability of heat-related admissions was expected and is consistent with previous studies, including slight asymmetry around the middle of summer with skewing in admissions towards the beginning of the summer due to acclimatisation as the season progresses. ${ }^{13,14}$ Similarly, the tendency for heat-related illness to occur in older people (median age of 52 years in the study) has been found in previous studies. ${ }^{8}$ Although the over-representation of males does not seem to be common in previous studies, some of which have found more females than males affected by heat-related illness, two recent studies of sports and leisure-related heat illness and injury have found an excess of hospitalisations for males, suggesting participation in sports and leisure activities may have contributed to the gender difference found in the study. ${ }^{8,15,16}$

Previous research suggests that there may be some underreporting of medications as an external cause. For example, in comparison to $2.4 \%$ in the present study, another study found a large proportion of heat-related admissions involved one or more medications, such as diuretics (46\%) and major tranquillisers (13\%), which are risk factors for heat-related illness. ${ }^{8}$

\section{Acknowledgments}

The assistance of Frank Siciliano is gratefully acknowledged. We thank John Agland (Manager, Information Analysis and Dissemination Unit, NSW Department of Health) for assistance with access to the ISC. The study was funded by the Macquarie University Research Development Grant Scheme.

\section{References}

1. Poumadère M, Mays C, Le Mer S, Blong R. The 2003 heat wave in France: dangerous climate change here and now. Risk Anal 2005; 25(6): 1483-94. doi:10.1111/j.1539-6924.2005. 00694.x

2. Kovats RS, Ebi KL. Heatwaves and public health in Europe. Eur J Public Health 2006; 16(6): 592-9. doi:10.1093/eurpub/ ck1049

3. Confalonieri U, Menne B, Akhtar R, Ebi KL, Hauengue M, Kovats RS et al. Human health. In: Parry ML, Canziani OF, Palutikof JP, van der Linden PJ, Hanson CE, editors. Climate Change 2007: Impacts, Adaptation and Vulnerability. Contribution of Working Group II to the Fourth Assessment Report of the Intergovernmental Panel on Climate Change. Cambridge: Cambridge University Press; 2007, pp. 391-431. Available from: http://www.ipcc.ch/pdf/assessment-report/ ar4/wg2/ar4-wg2-chapter8.pdf

4. Michelozzi P, De Sario M, Accetta G, de'Donato F, Kirchmayer U, D'Ovidio M, Perucci CA on behalf of HHWWS collaborative group. Temperature and summer mortality: geographical and temporal variations in four Italian cities. J Epidemiol Community Health 2006; 60(5): 417-23. doi:10.1136/jech.2005.040857

5. Vaneckova P, Hart MA, Beggs PJ, de Dear RJ. Synoptic analysis of heat-related mortality in Sydney, Australia, 1993-2001. Int J Biometeorol 2008; 52(6): 439-51. doi:10.1007/s00484-007-0138-z

6. Conti S, Meli P, Minelli G, Solimini R, Toccaceli V, Vichi M et al. Epidemiologic study of mortality during the summer 2003 heat wave in Italy. Environ Res 2005; 98(3): 390-9. doi:10.1016/j.envres.2004.10.009

7. Fouillet A, Rey G, Laurent F, Pavillon G, Bellec S, Guihenneuc-Jouyaux C et al. Excess mortality related to the August 2003 heat wave in France. Int Arch Occup Environ Health 2006; 80(1): 16-24. doi:10.1007/s00420006-0089-4

8. Faunt JD, Wilkinson TJ, Aplin P, Henschke P, Webb M, Penhall RK. The effete in the heat: heat-related hospital presentations during a ten day heat wave. Aust $N Z J$ Med 1995; 25(2): 117-21. doi:10.1111/j.1445-5994.1995. t602822.x

9. Díaz J, Jordán A, García R, López C, Alberdi JC, Hernández E et al. Heat waves in Madrid 1986-1997: effects on the health of the elderly. Int Arch Occup Environ Health 2002; 75(3): 163-70. doi:10.1007/s00420-001-0290-4

10. Carter R III, Cheuvront SN, Williams JO, Kolka MA, Stephenson LA, Sawka MN et al. Epidemiology of hospitalizations and deaths from heat illness in soldiers. Med Sci Sports Exerc 2005; 37(8): 1338-44. doi:10.1249/ 01.mss.0000174895.19639.ed

11. NSW Health. NSW Health Data Collections: Inpatient Statistics Collection. North Sydney: NSW Health; 2003. Available from: http://www.health.nsw.gov.au/im/ims/isc/ (Cited 16 January 2008.)

12. Australian Bureau of Statistics. 1217.0.55.001 - Glossary of Statistical Geography Terminology, 2003. Canberra: Commonwealth of Australia; 2004. Last updated 8 December 2006. Available from: http://www.abs.gov.au/AUSSTATS/ abs@.nsf/ProductsbyCatalogue/32EB1B908521AD75CA2571 220079FEEE?OpenDocument 
13. Lugo-Amador NM, Rothenhaus T, Moyer P. Heat-related illness. Emerg Med Clin North Am 2004; 22(2): 315-27. doi:10.1016/j.emc.2004.01.004

14. Khosla R, Guntupalli KK. Heat-related illnesses. Crit Care Clin 1999; 15(2): 251-63. doi:10.1016/S0749-0704(05)70053-1

15. Driscoll TR, Cripps R, Brotherhood JR. Heat-related injuries resulting in hospitalisation in Australian sport.
J Sci Med Sport 2008; 11(1): 40-7. doi:10.1016/ j.jsams.2007.04.003

16. Finch CF, Boufous $\mathrm{S}$. The descriptive epidemiology of sports/leisure-related heat illness hospitalisations in New South Wales, Australia. J Sci Med Sport 2008; 11(1): 48-51. doi:10.1016/j.jsams.2007.08.008

\section{NSW Public Health Bulletin Subscription Form and Electronic Early Alert Service}

To subscribe to the hard copy of the NSW Public Health Bulletin or to change your subscription details please complete this form and return it by email (phbulletin@doh.health.nsw.gov.au) or fax (61 29391 9232).

The Bulletin can be accessed electronically from www.publish.csiro.au/journals/phb. Subscribe to the Early Alert service to be notified as soon as it appears online (http://publish.csiro.au/nid/226.htm?nid=25\&aid=685).

\section{Subscription information}

$\square$ I wish to receive the NSW Public Health Bulletin:

My details are as follows

Name:

Organisation:

Mailing Address:

State: Postcode: Country:

Telephone: Facsimile:

Email:

\section{Change of Address}

I wish to change my mailing details, as follows:

Name:

From: [Insert old address]

To: [Insert new address] 